\title{
Iatrogenic Iron Overload in Dialysis Patients at the Beginning of the 21st Century
}

\author{
Guy Rostoker ${ }^{1,4} \cdot$ Nosratola D. Vaziri ${ }^{2} \cdot$ Steven Fishbane $^{3}$
}

Published online: 18 April 2016

(c) The Author(s) 2016. This article is published with open access at Springerlink.com

\begin{abstract}
Iron overload used to be considered rare in hemodialysis patients but its clinical frequency is now increasingly realized. The liver is the main site of iron storage and the liver iron concentration (LIC) is closely correlated with total iron stores in patients with secondary hemosideroses and genetic hemochromatosis. Magnetic resonance imaging is now the gold standard method for LIC estimation and monitoring in non-renal patients. Studies of LIC in hemodialysis patients by quantitative magnetic resonance imaging and magnetic susceptometry have demonstrated a strong relation between the risk of iron overload and the use of intravenous (IV) iron products prescribed at doses determined by the iron biomarker cutoffs contained in current anemia management guidelines. These findings have challenged the validity of both iron biomarker cutoffs and current clinical guidelines, especially with respect to recommended IV iron doses. Three long-term observational studies have recently suggested
\end{abstract}

Guy Rostoker

rostotom@orange.fr

1 Division of Nephrology and Dialysis, Hôpital Privé Claude Galien, Ramsay-Générale de Santé, Quincy sous Sénart, France

2 Division of Nephrology and Hypertension, University of California, Irvine, CA, USA

3 Division of Nephrology, Hofstra North-Shore-LIJ School of Medicine, Great Neck, New York, NY, USA

4 Service de Néphrologie et de Dialyse, HP Claude Galien, 20 route de Boussy, Quincy sous Sénart 91480, France that excessive IV iron doses may be associated with an increased risk of cardiovascular events and death in hemodialysis patients. We postulate that iatrogenic iron overload in the era of erythropoiesis-stimulating agents may silently increase complications in dialysis patients without creating frank clinical signs and symptoms. High hepcidin-25 levels were recently linked to fatal and nonfatal cardiovascular events in dialysis patients. It is therefore tempting to postulate that the main pathophysiological pathway leading to these events may involve the pleiotropic master hormone hepcidin (synergized by fibroblast growth factor 23), which regulates iron metabolism. Oxidative stress as a result of IV iron infusions and iron overload, by releasing labile non-transferrin-bound iron, might represent a 'second hit' on the vascular bed. Finally, iron deposition in the myocardium of patients with severe iron overload might also play a role in the pathogenesis of sudden death in some patients. 


\section{Key Points}

Almost all hemodialysis patients treated with erythropoeisis-stimulating agents receive parenteral (intravenous) iron to ensure sufficient available iron during therapy.

Until recently, iron overload was considered exceptional in dialysis patients in the era of erythropoeisis-stimulating agents. Quantitative hepatic magnetic resonance imaging is now the gold standard for iron store estimation and monitoring in non-renal-patients with secondary hemosideroses and genetic hemochromatosis.

Recent hepatic magnetic resonance imaging studies of dialysis patients revealed a high frequency of iron overload and suggest a strong link between the cumulative dose of intravenous iron and the risk of hemosiderosis. The potential iron overload toxicity is now one of the most controversial topics in the management of anemia in dialysis patients.

\section{Introduction}

Routine use of recombinant erythropoeisis-stimulating agents (ESA) over the past three decades has enabled anemia to be partially corrected in most patients with endstage renal disease (ESRD), thereby improving their quality of life and reducing the need for blood transfusion [1]. ESA use frequently leads to iron deficiency, owing to massive transfer of stored iron to erythroid progenitor cells [2], inadequate iron mobilization from repleted storage sites (resulting in functional iron deficiency), and blood loss related to hemodialysis itself, and also to routine blood sampling for laboratory tests and occult fecal bleeding owing to uremic enteropathy [1-3]. In fact, most ESAtreated hemodialysis patients receive parenteral iron to ensure sufficient available iron before and during ESA therapy $[3,4]$. Therefore, the twin risks of iron deficiency and iron overload must be tightly controlled in dialysis patients on iron therapy. Significantly, most studies published in the last two decades have focused on the detection and treatment of iron deficiency in dialysis patients, while very few have dealt with iron overload $[3,5]$. Thus, until recently, iron overload among dialysis patients was widely considered to be more prevalent during the pre-ESA era, when blood transfusion was often used to treat anemia and intravenous iron was given without concomitant ESA. As a result, iron overload was considered rare or exceptional in the ESA era, yet it is now increasingly recognized as a problematic clinical issue [3, 6-9]. The liver is the main site of iron storage, and the liver iron concentration (LIC) is closely correlated with total body iron stores in patients with secondary forms of hemosiderosis such as thalassemia major, sickle cell disease, and genetic hemochromatosis [10]. Hepatic magnetic resonance imaging (MRI) is now the gold standard for iron store estimation and monitoring in patients with secondary hemosideroses and genetic hemochromatosis [10]. Recent quantitative magnetic susceptometry and MRI studies of dialysis patients suggest a strong link between the cumulative dose of intravenous (IV) iron and the risk of iron overload, and also challenge both iron biomarker cutoffs and clinical guidelines, especially with respect to recommended iron doses [8, 11]. Three epidemiological studies recently suggested that excessive IV iron may increase mortality and cardiovascular events in hemodialysis patients [12-14]. These findings have led to editorials and position articles highlighting the potential dangers of excessive use of IV iron products $[9,15,16]$ and the inadequacy of guidelines proposed by KDIGO-2012 (Kidney Disease Improving Global Outcomes) and the iron biomarker targets set by KDOQI-2006 (Kidney Disease Outcomes Quality Initiative) and the EDTA-ERA-2009 (European Dialysis and Transplant Association-European Renal Disease) in protecting ESRD patients from iron overload [4, 17, 18]. They also contributed greatly to the organization of the KDIGO Controversies Conference on iron management in chronic kidney disease (CKD), which took place in San Francisco on March 27-30, 2014 [19]. This conference was attended by nephrologists, hematologists, hepatologists, and specialists in iron metabolism. Its consensus statements recognized the 'iron overload' entity in hemodialysis patients and called for a specific research agenda [19]. Finally, in June 2015, the Dialysis Advisory Group of the American Society of Nephrology published an aggiornamento on high 'blind' use of IV iron in hemodialysis patients [20]. It is noteworthy that the Japanese Society for Dialysis had already proposed, some years ago, that dialysis patients should receive a minimal amount of IV iron (no more than $650 \mathrm{mg}$ in the induction phase), only if they had true iron deficiency (ferritin $<100 \mu \mathrm{g} / \mathrm{L}$ ), and also warned against maintenance intravenous iron therapy for fear of toxicity [21]. This general review examines recent findings in this field, lying at the crossroads of iron metabolism and drug toxicity, nephrology, hematology, hepatology, and radiology, and their potentially important implications for the management and well-being of some 2 million hemodialysis patients worldwide. 


\section{Iron Metabolism}

Total iron stores average $2.2-3.5 \mathrm{~g}$ in healthy women and 3-4 $\mathrm{g}$ in men [22]. Nearly two-thirds of this iron is sequestered in the hemoglobin molecules of circulating erythrocytes and, to a lesser degree, in medullary erythrocytes. Another $20 \%$ is held in the liver (in hepatocytes and Kupffer cells) or in the reticulo-endothelial system (mainly in splenic macrophages), predominantly in the form of the iron-storage protein ferritin (marginally as hemosiderin), while muscle myoglobin accounts for a further $10 \%$ [22]. Iron-containing enzymes contain only $1 \%$ of iron stores, and circulating transferrin-bound iron represents only $0.2 \%(3 \mathrm{mg})$ [22]. Each day, reticulo-endothelial macrophages recycle about 20-30 mg of iron coming from senescent erythrocytes, covering the $20-30 \mathrm{mg}$ of iron required for normal erythropoiesis [22]. Physiological iron losses are estimated to be about $1 \mathrm{mg} /$ day (urine $0.1 \mathrm{mg} /$ day; enterocyte desquamation $0.6 \mathrm{mg} /$ day, skin $0.3 \mathrm{mg} /$ day). In women, these losses are increased by menstruation (the leading cause of iron-deficiency anemia worldwide), pregnancy, and breast-feeding [23]. Recommended dietary iron intake is about $10 \mathrm{mg} / \mathrm{day}$ (only about $10 \%$ of dietary iron is absorbed), rising to $30 \mathrm{mg} /$ day for pregnant and nursing women [23].

Hepcidin-25 is the master hormone of iron metabolism. It is synthesized in the liver and acts negatively on both intestinal iron absorption and iron release from reticuloendothelial macrophages and liver cells by reducing the expression of ferroportin, a protein that regulates iron export out of these cells [22]. Iron itself and inflammation (via interleukin-6) enhance hepcidin-25 synthesis, while anemia, hypoxia, bleeding, iron deficiency, erythropoietin, and increased medullary erythropoïesis all down-regulate hepcidin-25 synthesis [22]. The mechanism by which erythropoietic stimulation after blood loss down-regulates hepcidin synthesis was recently linked to a new peptide hormone, erythroferrone, which is secreted by erythroblasts and acts directly on the liver [24]. Deficient hepcidin-25 synthesis plays a central role in genetic hemochromatosis, whereas unregulated hepcidin synthesis is responsible for a newly discovered genetic (autosomal recessive) form of iron-deficiency anemia called IRIDA (iron refractory iron deficiency anemia) owing to a mutation of the TMPRSS6 gene that encodes matriptase-2 [10, 25]. IRIDA is refractory to oral iron but responds partially to IV iron administration [25].

\section{Blood Losses Due to Hemodialysis}

Blood losses are a major factor in iron deficiency associated with dialysis but have largely been overlooked since the advent of ESA and IV iron products. There are three cumulative sources of blood loss in hemodialysis patients: (1) the dialysis technique; (2) regular blood sampling for laboratory tests, and (3) occult intestinal bleeding owing to uremic enteropathy. Blood losses in this setting have traditionally been estimated at between 4 and $12 \mathrm{~L}$ per year (2-6 $\mathrm{g}$ of iron per year, $1 \mathrm{~L}$ of blood containing about $500 \mathrm{mg}$ of iron, but this may be an over-estimation because of the lower hematocrit of dialysis patients, resulting in a lower iron content) [26]. This approximation clearly overestimates dialysis-related blood losses. Moreover, the vascular access and comorbidities strongly influence the sources and amount of blood loss.

Blood loss has been estimated at $0.3 \mathrm{~mL} / \mathrm{session}$ [27] and $0.9 \mathrm{~mL} / \mathrm{session}$ [28] with modern dialysis membranes, and blood-line losses at $0.2 \mathrm{~mL} / \mathrm{session}$ [27]. Thus, assuming losses of $1.1 \mathrm{~mL}$ per session, annual losses owing to the hemodialysis technique itself during conventional hemodialysis (3 sessions/week, 150 sessions/year) represent about $165 \mathrm{~mL}$ (Table 1). With daily dialysis, this volume reaches between $330 \mathrm{~mL}$ (6 sessions/week) and $385 \mathrm{~mL}$ ( 7 sessions/week). At the 2014 Annual Meeting of the American Society of Nephrology, Japanese researchers reported similar volumes: residual blood in the tubing set and dialyser (measured by atomic spectrometry in 238 patients) represented an average loss of $1245 \mu \mathrm{g}$ of iron per dialysis session [29].

However, one of the main sources of blood loss in dialysis units is related to the care of (tunnelized) doublelumen catheters by nurses applying a universal purge protocol $(7-10 \mathrm{~mL}$ of blood in each catheter branch at the outset of the session), which leads to annual blood loss of $2.4 \mathrm{~L}$. An additional $288 \mathrm{~mL}$ should be added for routine monthly bacterial culture of anticoagulant locks when this practice is employed. Thus, total annual blood loss linked to the use of a double-lumen catheter is about $2.7 \mathrm{~L}$ (Table 1) [30]. Note that the use of a recent protocol proposed by Prof. Bernard Canaud, based on a purge of only $2 \mathrm{~mL}$ per branch, would reduce catheter-related blood loss to only $888 \mathrm{~mL} /$ year (-77\%) [30]. Finally, sudden

Table 1 Blood losses in hemodialysis patients [30]

\begin{tabular}{ll}
\hline $\begin{array}{l}\text { Related to the dialytic technique } \\
\text { (membrane + blood lines) }\end{array}$ & $165 \mathrm{~mL}$ of blood/year \\
$\begin{array}{l}\text { Occult gut (micro) bleeding } \\
\text { Regular blood sampling for } \\
\text { biological follow-up }\end{array}$ & $2257 \mathrm{~mL}$ of blood/year \\
Care of double-lumen catheters & $428 \mathrm{~mL}$ of blood/year \\
$\begin{array}{l}\text { In summary (vignette) } \\
\text { Patient with a native fistula } \\
\text { Patient with a long-lasting } \\
\text { double-lumen catheter }\end{array}$ & $2680 \mathrm{~mL}$ of blood/year \\
\hline
\end{tabular}


accidental bleeding owing to insufficient compression or high internal pressure of a native fistula may cause additional, severe blood loss [30].

Regular blood sampling is the second major source of blood loss in this setting. In a recent French survey, routine blood sampling was quantified at between 350 and $450 \mathrm{~mL} /$ year in ten dialysis centers run by the RAMSAYGénérale de Santé healthcare provider [30], a volume close to that found by Sargent and Acchiardo $(368 \mathrm{~mL})$ at the University of Tennessee in Memphis in 2004 [26, 30] (Table 1). Blood sampling for routine follow-up has been estimated at $600 \mathrm{~mL} /$ year in Japan [29]. Note that blood sampling can be markedly increased by participation in clinical trials and pathophysiological studies.

The third source of blood loss is occult gut bleeding, which is below the detection limit of classical stool tests. This is favored by uremic enteropathy, uremic platelet dysfunction, and anticoagulation of the extracorporeal circuit [31]. In the 1980s, Rosenblatt and co-workers, using chromium 51-labeled erythrocytes, quantified fecal blood loss at $0.83 \mathrm{~mL} /$ day in healthy controls, $3.15 \mathrm{~mL} /$ day in non-dialysed CKD patients, and $6.27 \mathrm{~mL} /$ day $(2.2 \mathrm{~L} /$ year $)$ in hemodialysis patients [31] (Table 1). These losses are increased by antiplatelet drugs and vitamin $\mathrm{K}$ antagonists, which necessitate the use of higher IV iron dosages to replenish iron stores (e.g,. 703-961 mg of additional IV iron per year) $[32,33]$.

A hemodialysis patient with a native arteriovenous fistula, treated in a non-academic dialysis center without antiplatelet drugs or vitamin $\mathrm{K}$ antagonists, can thus be expected to lose $2.85 \mathrm{~L}$ of blood per year $(1.425 \mathrm{~g}$ of iron/ year), whereas a patient with the same clinical profile but a double-lumen tunnelized catheter will lose $5.5 \mathrm{~L}$ of blood or $2.765 \mathrm{~g}$ of iron per year. Even this latter figure is far below the classical estimate of between $2 \mathrm{~g}$ and $6 \mathrm{~g} / \mathrm{year}$ (Table 1) [30].

\section{Intravenous (IV) Products}

Iron deficiency is an important clinical concern in CKD patients, especially hemodialysis patients, as it gives rise to superimposed iron-deficiency anemia and impairs various cellular functions. Oral supplementation, in particular with ferrous salts, is associated with a high rate of gastrointestinal adverse effects in this setting and is poorly absorbed, a problem that is avoided with IV iron products [30]. Recently, the European Medicines Agency's Committee for Medicinal Products for Human Use took measures to minimize the risk of (rare) allergic reactions to IV iron products by modifying the summaries of product characteristics, allowing IV iron infusions to take place only in public or private hospitals, and imposing clinical monitoring for at least $30 \mathrm{~min}$ after the infusions [30]. Seven different IV iron pharmaceuticals are available today in the USA and Europe and in other industrialized countries: their main physicochemical and pharmacokinetic characteristics are summarized in Table 2. The most recent and stable IV iron complexes (low-molecular-weight iron dextran, ferric carboxymaltose, iron isomaltoside 1000, and ferumoxytol) can be given at higher single doses and more rapidly than older preparations such as iron sucrose (Table 2) [30,34]. The larger size of the carbohydrate shell of some recent IV iron pharmaceuticals (low-molecular weight dextran and ferumoxytol) increases the risk of anaphylaxis, although it remains rare [35]. Test doses may be advisable for low-molecular-weight iron dextran but are no longer mandatory [30, 34]. Iron supplementation is recommended for all CKD patients with iron-deficiency anemia and those who receive erythropoiesis-stimulating agents, whether or not they require dialysis $[4,17,18]$. Parenteral iron therapy has gained popularity in the nephrology community in the last 15 years and the IV route has for many years been the preferred route of administration to hemodialysis patients because of its convenience (infusion during dialysis sessions), its superiority over oral preparations for treating true iron deficiency, and its ability to overcome functional iron deficiency, a very common clinical situation in dialyzed CKD [1, 4, 17, 18]. Indeed, randomized trials in hemodialysis patients showed significantly greater increases in hemoglobin levels with IV iron as compared with oral iron, and a low rate of treatment-related adverse events during these albeit short trials $[1,17]$. In addition, IV iron products enable cost savings of about $20-30 \%$ by sparing expensive ESA products [36]. It is also noteworthy that the recent meta-analysis performed by the Cochrane network comparing parenteral vs. oral iron concluded that the 28 included studies (2098 participants) provided strong evidence for larger increases in ferritin (mean difference: $243 \mu \mathrm{g} / \mathrm{L}, 95 \%$ confidence interval (CI) 188-297) and transferrin saturation (mean difference: $10.2 \%$; $95 \%$ CI 5.5-14.8), together with only a moderate increase in hemoglobin (mean difference: $0.9 \mathrm{~g} / \mathrm{dL} ; 95 \%$ CI 0.44-1.37) in the IV iron-treated groups [37]. The authors also noted that adverse effects were adequately reported in only $50 \%$ of included studies and suggested the need for further studies with patient-centered outcomes to assess the real benefit of guideline-advocated strategies for reducing ESA doses and costs through the use of IV iron; they further underlined the need to prove the lack of serious adverse effects of these pharmaceuticals [37]. With the exception of iron gluconate and ferumoxytol, which are specially indicated in CKD patients with iron deficiency, IV iron pharmaceuticals are only indicated for use in the general case of iron deficiency anemia (whatever the 


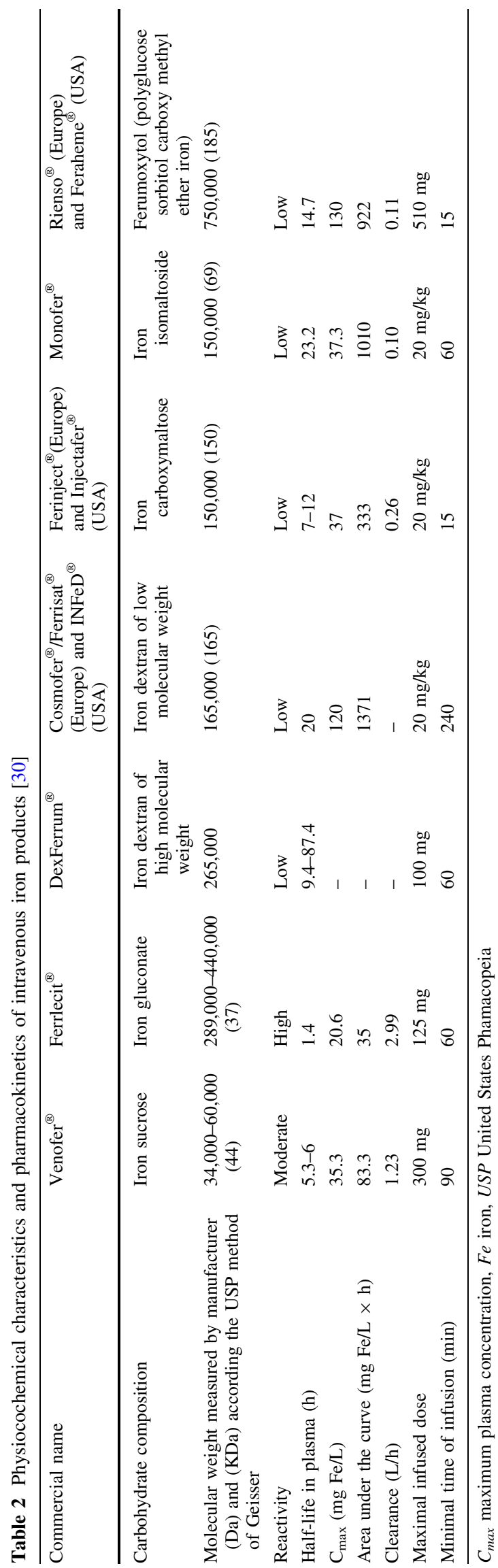

underlying disease) when oral iron is unavailable, ineffective, or poorly tolerated, or as a first-line treatment when there is a clinical need to rapidly replenish iron stores (iron sucrose and low-molecular-weight iron dextran) [38]. Moreover, iron overload represents a formal contraindication to begin or pursue therapy with these IV iron products, as stressed in the Contraindications or Precautions section of the summaries of product characteristics [38].

\section{Evolving Concept of Iron Therapy in Hemodialysis Patients over the Past Two Decades, and the Increased Use of IV Iron Products Worldwide}

When erythropoietin replacement therapy became possible in the late 1980s, the goal of iron therapy was to maintain iron stores, allowing true iron deficiency to be prevented, mainly with oral iron supplements, usually in patients with serum ferritin levels below $50 \mu \mathrm{g} / \mathrm{L}[39,40]$. Parenteral iron was considered only a second-line option when oral iron drugs were poorly tolerated or ineffective, or when severe iron deficiency was present [39-41].

Based solely on bone marrow studies and short-term tolerability in controlled trials of IV iron products, recent guidelines of the Kidney Disease Outcomes Quality Initiative (KDOQI) in the USA in 2006, endorsed by the European Renal Best Practice (ERBP) of the European Renal Association EDTA-ERA redefine iron deficiency (ferritin $<100 \mu \mathrm{g} / \mathrm{L}$ instead of $50 \mu \mathrm{g} / \mathrm{L}$ ) and adopt even higher iron-store repletion criteria (ferritin target $>250$ and $<500 \mu \mathrm{g} / \mathrm{L}$ ) $[4,18]$.

The KDIGO 2012 guideline set the upper ferritin limit at $500 \mu \mathrm{g} / \mathrm{L}$ for hemodialysis patients, underlined the risk of functional iron deficiency during ESA treatment, and emphasized the ability of IV iron to avoid the use of ESA [17]. It even advocated a trial of IV iron prior to ESA [17].

These clinical guidelines, which are largely followed and often exceeded by nephrologists worldwide, have clearly contributed to the excessive use of parenteral iron in hemodialysis patients $[4,17,18]$. An epidemiological study of anemia management in American hemodialysis patients, based on the United States Renal Data System register, showed that the use of IV iron rose from $64 \%$ of patients in 2002 to $76 \%$ in 2008, while the infused dose rose from 166 to $216 \mathrm{mg} / \mathrm{month}$ over the same period [42]. Yet the usual monthly dose of IV iron during the first year of hemodialysis was even higher, ranging from $270 \mathrm{mg}$ to $305 \mathrm{mg} / \mathrm{month}$ [42]. Furthermore, the US Food and Drug Administration modified the ESA label in June 2010, leading to a rise in the proportion of US patients receiving IV iron from $57 \%$ in August 2010 to $71 \%$ in August 2011, and to a significant decline in ESA dosages [43]. The median ferritin level rose from 556 to $650 \mu \mathrm{g} / \mathrm{L}$, and $34 \%$ 
of patients had values exceeding $800 \mu \mathrm{g} / \mathrm{L}$ [43]. Nearly one in five dialysis patients received more than $500 \mathrm{mg} / \mathrm{month}$ during this period [43].

Similar trends in the use of IV iron in other industrialised countries were recently reported, with the exception of Japan. Overall, the percentage of patients who received IV iron rose between 1999 and 2010 from 50 to $71 \%$ (from 65 to $80 \%$ in Canada; from 55 to $70 \%$ in France, from 65 to $80 \%$ in Germany, and from 60 to $80 \%$ in the UK) [44]. Between 1999 and 2010, the mean ferritin level increased in most countries (from 380 to $450 \mu \mathrm{g} / \mathrm{L}$ in Canada, from 420 to $580 \mu \mathrm{g} / \mathrm{L}$ in Germany, and from 400 to $500 \mu \mathrm{g} / \mathrm{L}$ in the UK) but remained stable in France (around $400 \mu \mathrm{g} / \mathrm{L}$ ) [44]. In Japan, the proportion of patients receiving IV iron rose only from 25 to $36 \%$, while the mean ferritin level increased only from 280 to $320 \mu \mathrm{g} / \mathrm{L}$ [44]. Overall, in industrialized countries outside the USA, the average monthly dose of IV iron infused during hemodialysis sessions rose by $21 \%$, from $232 \mathrm{mg} / \mathrm{month}$ in 1992 to $281 \mathrm{mg} / \mathrm{month}$ in 2010 [44].

Of note, the recent Dialysis Outcomes and Practice Patterns Study (DOPPS)-Monitor study (9735 patients in 91 US facilities) showed a decrease in the amount of IV iron infused, from $280 \mathrm{mg} / \mathrm{month}$ in 2011 to $200 \mathrm{mg} / \mathrm{month}$ in 2012, with a similar value in 2013 [45].

Of note, there are no data to show that cumulative doses of IV iron per individual exceed estimated losses. Moreover, the KDIGO controversies conference agenda stressed the need for studies to quantify blood losses in dialysis patients, especially from the intestinal tract, in the era of widespread use of low-molecular-weight heparin anticoagulation of the extracorporeal circuit, which may reduce occult gut bleeding, and, at the opposite end of the spectrum, in patients on antiplatelet agents and vitamin $\mathrm{K}$ antagonists, who lose more blood [19].

\section{Lessons Learned From Hemodialysis-associated Hemosiderosis in the Pres-ESA Era}

The poor prognosis of ESRD in the pre-ESA era, together with the severity of dialytic complications (especially fullblown clinical iron overload owing to transfusions and sole use of IV iron products), provided valuable lessons on the use of iron supplements, mainly based on autopsy studies [3]. Indeed, post-mortem studies of dialysis patients with severe hepatosplenic sideroses in the late 1970s and early 1980s showed abundant iron deposits in the liver, spleen, adrenal glands, lymph nodes, and lungs, with generally smaller amounts in the kidneys, pancreas, and heart [4648]. The earliest detectable hepatic iron deposits were found in cells lining the sinusoids and in Kupffer cells [46]. As hepatic siderosis progressed, iron started to appear in hepatocytes, initially at the periphery of hepatic lobules close to portal triads and then throughout the lobule [46]. The main iron storage site in the spleen was in the cells lining the splenic sinusoids, whereas the white pulp was usually spared [46]. Even massive hepatic siderosis was not apparently associated with cell damage, although reticulin and trichrome staining showed a more abundant fibroconnective framework and a loss of liver cells [46-48]. Of note, liver enzymes were seldom increased in patients with hepatic siderosis [47] and cirrhosis was rare [46-48]. Indeed, liver biopsy showed focal portal fibrosis in most patients with marked hemosiderosis [49], suggesting that the risk threshold for hepatic cirrhosis in iron-overloaded dialysis patients is high in the absence of coexisting viral hepatitis [46-49].

Importantly, post-mortem studies showed that iron overload was strongly linked to blood transfusion and also to the use of IV iron (high-molecular-weight iron dextran, Imferon ${ }^{\circledR}$ ); the closest relationship was between hepatic siderosis and the use of IV iron [6, 47, 48]. Patients who received little or no IV iron were usually free of iron overload, and massive hepatosplenic siderosis was only seen in patients who had been on dialysis for more than 3 years [6, 47, 48]. Adrenal involvement was observed in respectively $5 \%(11 / 24)$ of unselected patients studied by Pitts et al. [47], compared with $94 \%$ (17/18) of patients with severe hepatosplenic siderosis studied by Ali [46]. Pancreas involvement was found in only $7 / 24$ patients (29\%) studied by Pitts and co-workers and in 5/18 patients (27\%) with severe hepatosplenic siderosis studied by Ali [46, 47]. Significant iron deposits were found in the heart of respectively, $16.6 \%(4 / 24)$ and $22 \%(5 / 22)$ of unselected patients in the autopsy studies of Pitts [47] and Gokal [48], but in $44 \%(8 / 18)$ of patients with severe hepatosplenic siderosis studied post-mortem by Ali [46].

At that time, one possible strategy to avoid transfusionrelated iron overload in dialysis patients with transfusiondependent anemia was to transfuse young rather than mature erythrocytes [49]. The only available iron chelator (deferoxamine/Desferal ${ }^{\circledR}$ ) was advocated to prevent hemosiderosis and to treat organ dysfunction owing to iron overload [49].

The arrival of recombinant human erythropoietin in the early 1990s represented a therapeutic revolution. It allowed anemia and iron overload to be treated simultaneously by inducing both massive mobilization of iron stores and effective phlebotomy (by partial letting of the extracorporeal circuit) at the end of the dialysis sessions in patients who had been rendered non-anemic [50]. The same period saw the first successful use of non-invasive radiological tools (quantitative computed tomography) for the diagnosis of hemodialysis-associated hemosiderosis and for monitoring liver iron stores [51]. 
Note that this classical (although rare) clinical picture of hemodialysis-associated hemosiderosis seen during the pre-ESA era has totally disappeared over the past three decades in industrialized countries.

\section{Non-invasive Imaging of Liver Iron Stores}

The liver is the main iron storage site and the LIC gives a very accurate picture of total body iron stores in patients with secondary hemosideroses such as thalassemia major, sickle cell disease, and genetic hemochromatosis [52, 53]. Non-invasive techniques for estimating liver iron stores have been developed to avoid liver biopsy, including the superconducting quantum interference device (SQUID), quantitative computed tomography, and MRI $[54,55]$. MRI is now the preferred technique, because of its reproducibility, sensitivity, availability, and ability to scan multiple organs in the same session [55]. Hepatic MRI is now the gold standard method for estimating and monitoring iron stores in non renal patients, providing 'iterative radiological biopsy' $[53,56]$.

The LIC may be the best marker of iron overload in ESRD: hemodialysis patients receiving IV iron in the pre-ESA era had paradoxically low bone marrow iron content in up to one-third of cases, despite severe hepatosplenic siderosis [6], suggesting that bone marrow analysis may not accurately quantify iron stores in dialysis patients, even in the ESA era [6].

SQUID (or magnetic susceptometry) is based on the magnetic volume susceptibility of paramagnetic ferritin/hemosiderin iron in the liver and was validated against percutaneous biopsy $[55,56]$. SQUID does not distinguish between ferritin and hemosiderin iron $[55,56]$. However, this method is not widely available (only five devices worldwide), very costly (about 1000-1500 euros per exam, and even more in the USA), and is characterized by the lack of calibration homogeneity (risk of LIC under-estimation) $[55,56]$.

Liver quantitative computer tomography has now given way to MRI [51, 54, 55]. Quantitative MRI is based on the paramagnetic properties of iron: the magnetic resonance signal falls as the LIC increases [55]. Like SQUID, MRI does not distinguish ferritin from hemosiderin iron [55]. The advantages of MRI include its low cost (about 300 euros per exam in Europe), non-irradiating nature, and availability. In addition, it does not require gadolinium and thus avoids the risk of gadolinium-associated nephrogenic fibrosis in CKD patients (a clinical situation mimicking scleroderma) [55].

There are three MRI modalities for liver iron assay in non-renal patients: the signal-intensity ratio, $\mathrm{R} 2$ relaxometry, and $\mathrm{R} 2 *$ relaxometry [55]. The signal intensity ratio method was first published in the Lancet in 2004, having been developed at Rennes University (France) on a 1.5-T apparatus [57]. This is the method most widely used in
Europe [58]. It was validated in a cohort of 191 patients with secondary hemosiderosis, genetic hemochromatosis, and hepatic disorders requiring liver biopsy for biochemical iron assay [57]. The Rennes University method was replicated, by comparison with liver biopsy, in three prospective cohorts in France, the Netherlands, and Spain [58-60]. It is based on a comparison of liver and muscle intensities in various sequences (T1, PD, T2, T2+, T2++), the results being analyzed with an algorithm that chooses the most sensitive and specific sequence depending on the severity of iron overload [57]. Free analytical software is available on the Rennes University website. This method has a sensitivity of $89 \%$ and a specificity of $80 \%$ for iron overload disease, and is linear up to $350 \mu \mathrm{mol} / \mathrm{g}$ of dry liver tissue [57]. An algorithm established by a Spanish team is required for values exceeding $350 \mu \mathrm{mol} / \mathrm{g}$ of dry liver tissue [60].

The second MRI method, based on R2 relaxometry, was developed on a 1.5-T apparatus in Australia in 2005 [61]. It was validated in a cohort of 105 patients with thalassemia, genetic hemochromatosis or hepatic disorders who had liver biopsy [61]. It was also favorably compared to SQUID in 23 patients [62]. This method based on R2/T2 sequences (commercial name Ferriscan) has a sensitivity of $86 \%$ and a specificity of $88 \%$ for iron overload disease. It is linear up to $700 \mu \mathrm{mol} / \mathrm{g}$ of dry liver, but the apparatus must be specifically configured and calibrated with phantoms [61]. It is principally used in Australia, New Zealand, and North America.

The third MRI technique for iron-store quantification is based on R2* relaxometry and can be used on a $1.5 \mathrm{~T}$ apparatus with specific software. This method not only quantifies liver iron but also detects iron overload in the heart, spleen, and pancreas in the same session (about 20-30 min) [63]. Its main limitation is that it has only been validated against a small number of liver biopsies $(22,30$, and 47 patients in the three available studies) [63-65]. Equations have also been proposed by Wood and by Pennell to transform the results into milligram of liver iron [63, 64]. Finally, specific MRI sequences can also give valuable information on liver fat and dysmorphia.

Normal MRI hepatic iron store values have been established on the basis of liver biopsy, together with categories of iron overload reflecting the risk of complications (Table 3) [10, 55]. According to Rennes University, LIC values between 40 and $100 \mu \mathrm{mol} / \mathrm{g}$ of dry liver tissue represent mild iron overload, between 101 and $200 \mu \mathrm{mol} / \mathrm{g}$ moderate iron overload, and $>201 \mu \mathrm{mol} / \mathrm{g}$ severe iron overload [57]. As the upper $95 \%$ of LIC in healthy adults is $32 \mu \mathrm{mol} / \mathrm{g}$ but hepatic MRI only accurately detects liver iron load exceeding $50 \mu \mathrm{mol} / \mathrm{g}$, the upper limit of normality has been set at $50 \mu \mathrm{mol} / \mathrm{g}$ for dialysis patients [8]. Therapeutic proposals for clinically relevant thresholds of MRI-determined LIC are included in hepatology and hematology guidelines for iron overload 
Table 3 Clinically relevant liver iron cut-offs for secondary hemosiderosis and genetic hemochromatosis [3]

\begin{tabular}{ll}
\hline $\begin{array}{l}\text { Liver iron content }(\mu \mathrm{mol} / \mathrm{g}) \\
(\mathrm{mg} / \mathrm{g})\end{array}$ & Clinical LIC cut-offs for iron-overload diseases \\
\hline $32 \mu \mathrm{mol} / \mathrm{g}(1.8 \mathrm{mg} / \mathrm{g})$ & $\begin{array}{l}\text { 95th percentile of healthy adults } \\
\text { Threshold for increased risk of iron-induced complications and level of } \\
\text { decision for chelation therapy (secondary hemosiderosis) or phlebotomy } \\
\text { (genetic hemochromatosis) }\end{array}$ \\
$125 \mu \mathrm{mol} / \mathrm{g}(7 \mathrm{mg} / \mathrm{g})$ & $\begin{array}{l}\text { Saturation threshold of the reticuloendothelial system in sickle cell disease } \\
\text { Risk threshold for hepatic fibrosis in sickle cell disease }\end{array}$ \\
$143 \mu \mathrm{mol} / \mathrm{g}(7 \mathrm{mg} / \mathrm{g})$ & $\begin{array}{l}\text { Risk threshold for hepatic fibrosis and cardiac disease in thalassemia major } \\
\text { Risk threshold for hepatic fibrosis or cirrhosis in patients with genetic } \\
260 \mu \mathrm{mol} / \mathrm{g}(9 \mathrm{mg} / \mathrm{g})\end{array}$ \\
$331 \mu \mathrm{mol} / \mathrm{g}(18 \mathrm{mg} / \mathrm{g})$ & hemochromatosis \\
\hline
\end{tabular}

LIC liver iron concentration diseases; examples include chelation for hemosiderosis and phlebotomy for genetic hemochromatosis, and also specific follow-up of target organs (Table 3) [10, 53-56].

There is currently a need to validate these MRI techniques for quantifying liver iron content specifically in dialysis patients, notably by comparison with liver biopsy. However, liver biopsy is an aggressive and risky invasive procedure, especially in frail ESRD patients, and such studies therefore raise ethical concerns. In our opinion, a prospective MRI study of dialysis patients requiring liver biopsy or liver surgery for their usual medical care could help to fill this knowledge gap.

Radiologists may be solicited in the near future by nephrology teams requesting quantitative hepatic MRI for research purposes, and later for diagnosis and follow-up of iron overload in dialysis patients. Radiologists and nephrologists should realize that there are marked differences in the pharmacokinetics of IV iron products, and that they can interfere with MRI (see Tables 2, 4) [66]. The required time interval between the last IV iron infusion and MRI ranges from 1 week (iron sucrose, iron gluconate, iron carboxymaltose) to 1 month (low-molecular-weight iron dextran and iron isomaltoside), 3 months (high-molecular-weight iron dextran) or even 6 months (ferumoxytol) if spurious results owing to magnetic interference are to be avoided (Table 4) [66]. The Pharmacological Committee of the European Medicines Agency modified the summary of product characteristics for ferumoxytol/Rienso ${ }^{\circledR}$ in 2015 after the literature review performed by Rostoker and Cohen, making a 6-month interval mandatory instead of the previous 3 months $[66,67]$.

\section{Iron Overload in Dialysis Patients in the ESA Era}

Studies using SQUID [11] and more recently quantitative MRI $[8,68,69]$ to estimate LIC in hemodialysis patients have provided new information on iron metabolism in advanced CKD and have underlined the potential risk of hemosiderosis. They also suggest a strong link between the infused iron dose and the risk of iron overload in this setting, challenging current guidelines with respect to the safety of IV iron at high repeated doses [4, 17, 18], as well as the reliability of iron biomarker cutoffs, and methods for monitoring iron stores in dialysis patients $[8,9,15,16]$.

Two recent MRI studies focused on iron overload in hemodialysis patients with serum ferritin levels far above $500 \mu \mathrm{g} / \mathrm{L}$ (the upper limit advocated by KDOQI-2006, EDTA-ERA-2009, and KDIGO-2012 guidelines): Ferrari et al. used R2 relaxometry to study 15 Australian patients with a median ferritin of $782 \mu \mathrm{g} / \mathrm{L}$ and found hepatic iron overload in two-thirds of cases [68]. Ghoti et al. used T2*MRI to measure liver and spleen iron content, and to search for pancreatic and cardiac iron deposits, in 21 ironoverloaded Israeli hemodialysis patients with serum ferritin levels over $1000 \mu \mathrm{g} / \mathrm{L}$ [69]. They found hepatic siderosis in $19 / 21$ patients $(90 \%)$ and spleen involvement in all 21 patients (100\%) [69]. Because of poor patient compliance with this specific exam, pancreatic involvement was sought in only the eight most highly motivated patients and was found in three cases (37\%) [69]. None of the patients had an abnormal cardiac R2* but few patients were studied and no conclusions can thus be drawn on the risk of cardiac iron deposits in patients with very high ferritin levels [69].

Two studies have analyzed LIC stores, one with SQUID in 2004 [11] and the other in 2012 with the Rennes University MRI protocol [8] in cohorts of hemodialysis patients treated according the KDOQI-2006 [4] and EDTAERBP-2009 guidelines [18] and with optimal ferritin levels (between 200 and $500 \mu \mathrm{g} / \mathrm{L}$ ). Canavese et al used SQUID to study liver iron stores in 40 Italian patients and found normal values in $30 \%$ of cases (median ferritin $245 \mu \mathrm{g} / \mathrm{L}$ ), mild iron overload in $32.5 \%$ (median ferritin $329 \mu \mathrm{g} / \mathrm{L}$ ) and moderate iron overload in $37.5 \%$ (median ferritin $482 \mu \mathrm{g} /$ L) [11]. It was claimed that these findings could not be extrapolated to the general hemodialysis population 


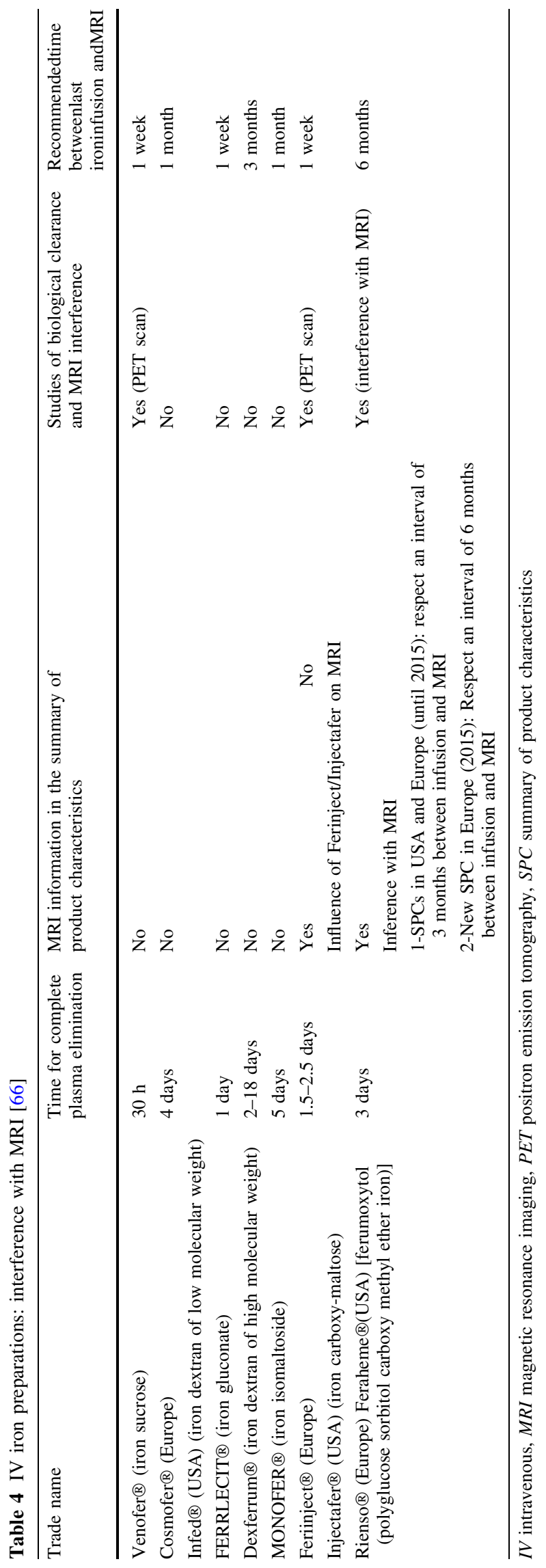

because of possibly biased selection of an iron-overloaded population [70].

Rostoker et al. recently showed hepatic iron overload on MRI $(>50 \mu \mathrm{mol} / \mathrm{g}$ dry weight) in $84 \%$ of 119 stable French hemodialysis patients treated according to current guidelines; iron overload was mild in 42 patients $(35.3 \%)$, moderate in $22(18.5 \%)$, and severe ( $>200 \mu \mathrm{mol} / \mathrm{g}$ dry weight) in $36(30 \%)$, at levels usually observed in genetic hemochromatosis (Fig. 1) [8]. MRI also showed spleen anomalies (a feature of secondary hemosiderosis) in several patients [8].

In the French cross-sectional study, LIC correlated with infused iron, hepcidin, and C-reactive protein values in univariate analysis $(p<0.05$, Spearman test) and in binary logistic regression $(p<0.05)$ [8]. No link was found between the LIC of hemodialysis patients with excessive alcohol consumption [Alcohol Use Disorders Test (AUDIT) score] and the major HFE mutation C282Y [8]. As in the SQUID study by Canavese [11], female individuals had an increased relative risk of iron overload (3.36; $95 \%$ CI 1.03-10.9) [8]. Eleven patients were closely monitored during parenteral iron therapy, showing that the monthly IV iron dose correlated strongly with both the overall and monthly increases in LIC (rho $=0.66, p=0.0306$ and rho $=0.85, p=0.0015$, respectively; Spearman's test) (Figs. 2 and 3) [8].

In the 33 longitudinally studied patients with iron overload, iron stores fell significantly after iron withdrawal or after a major reduction in the iron dose [first MRI: $220 \mu \mathrm{mol} /$ g (CI: 60-340); last MRI: $50 \mu \mathrm{mol} / \mathrm{g}$ (CI: 5-210); $p<0.0001$, Wilcoxon's paired test] (Fig. 3) [8]. The slope of the decline in hepatic iron was $-17.9 \mu \mathrm{mol} / \mathrm{g}$ dry weight/month after iron withdrawal, $-12.8 \mu \mathrm{mol} / \mathrm{g}$ dry weight/month after a major iron dose reduction, and $11.9 \mu \mathrm{mol} / \mathrm{g}$ dry weight/month after renal transplantation [8]. Thus, the frequency of iron overload might be vastly underestimated in hemodialysis patients receiving both ESA and IV iron; indeed, most hemodialysis patients receiving ESA and IV iron supplementation according to current guidelines appear to have hepatic iron overload in these LIC imaging studies $[8,11]$. We subsequently called for a revision of iron therapy guidelines for dialysis patients, notably regarding the amount of IV iron infused and non-invasive monitoring of iron stores $[8,9,16]$. It also should be noted that hepatic iron stores measured by MRI are a surrogate marker with as-yet unproven clinical relevance in dialysis patients in terms of mortality and morbidity.

These recent LIC imaging studies were performed at least 1 week [8, 11], 2 weeks [68], or months after the last iron infusion [69]. These findings reveal true liver iron thesaurosis and differ markedly from the rapid transient increase in the exchangeable compartment of iron described a few years ago by Beshara and coworkers using positron emission tomography scan technology after iron 
Fig. 1 Results of a crosssectional quantitative magnetic resonance imaging (MRI) study of 119 hemodialysis patients (according to [3] and [8])

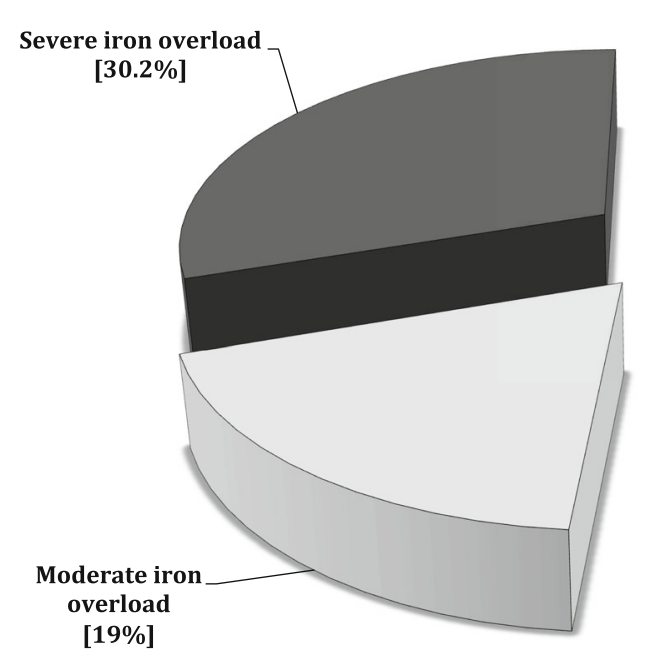

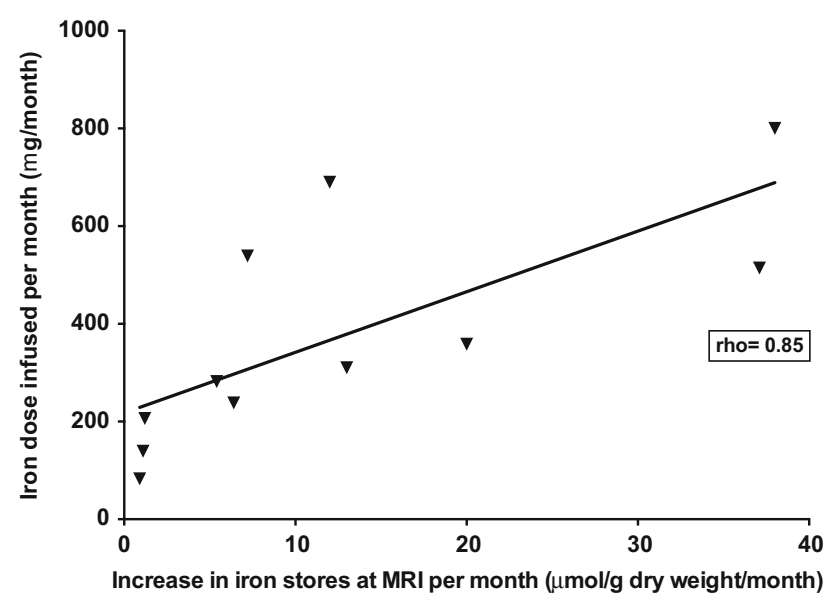

Fig. 2 Correlation between the infused iron dose and hepatic iron stores in 11 hemodialysis patients studied by quantitative magnetic resonance imaging (according to [8])

infusion [71-73]. In a minipig model, a large fraction of radiolabeled iron-sucrose reached the liver in as little as 30 mins after the infusion, and liver uptake was observed until $10 \mathrm{~h}$; release to bone marrow started after $11 \mathrm{~h}$ [71]. In six CKD patients with iron-deficiency anemia, strong liver uptake of labelled iron-sucrose started 20-60 min after the infusion and lasted up to $5 \mathrm{~h}$, with liver release of iron beginning at the sixth hour [72]. Similar but faster human liver kinetics has been reported with iron carboxymaltose, with a smaller fraction $(30 \%)$ transiently reaching the liver [73].

A recent Australian study reported use of the oral iron chelator deferasirox to treat iron overload in hemodialysis patients [74]. Classical clinical cases of hemodialysis-associated hemosiderosis (requiring deferoxamine/Desferal $^{\circledR}$ ) have recently been published by a nephrology team in Egypt and were attributed to the non use of ESA together with abundant blood transfusions and IV iron infusions [75]. This highlights the need (as done for antiretroviral therapy for AIDS in emerging countries) for pharmaceutical companies and international societies of nephrology and dialysis to make expensive ESA drugs available to dialysis patients living in these countries.

It is of note that the safety and efficacy of IV iron products in dialysis patients, as stated in their respective labels [38] (e.g., induction phase for the most widely used pharmaceuticals: iron sucrose $100-300 \mathrm{mg} /$ week for a total dose of $1-1.2 \mathrm{~g}$, possibly repeated up to $2-2.4 \mathrm{~g}$; iron carboxymaltose and iron isomaltoside $200 \mathrm{mg} /$ dialysis session with a cumulative dose of $1-2 \mathrm{~g}$ according to the hemoglobin level and body weight), may be at odds with the clinical practice of strong iron store repletion, as advocated by current guidelines (KDOQI 2006, ERBP 2009, KDIGO 2012) [4, 17, 18]. Moreover, most labels give imprecise information, or none at all, on the maintenance phase; only the French label for iron sucrose (because of the decentralized EMA approval procedure) indicates a dose of $2 \mathrm{mg} / \mathrm{kg}$ once or twice per month, guided by careful biological monitoring of iron biomarkers [38]. This latter point was put forward in 2013 by the French Medicines Agency (ANSM) after analysing the publication of Rostoker and co-workers performed in a dialysis center in the Paris area: ANSM stated that although hemodialysis patients in this study were correctly treated according to current guidelines, the iron sucrose doses clearly exceeded those allowed by the label, underlining an inconsistency between the French iron sucrose label and anemia guidelines (KDOQI and ERBP) [8, 76]. Convergently, the Dialysis Advisory Group of the American Society of Nephrology recently considered that largely unanswered questions remain concerning the doses of iron to administer, the optimal dosing regimen, and iron 


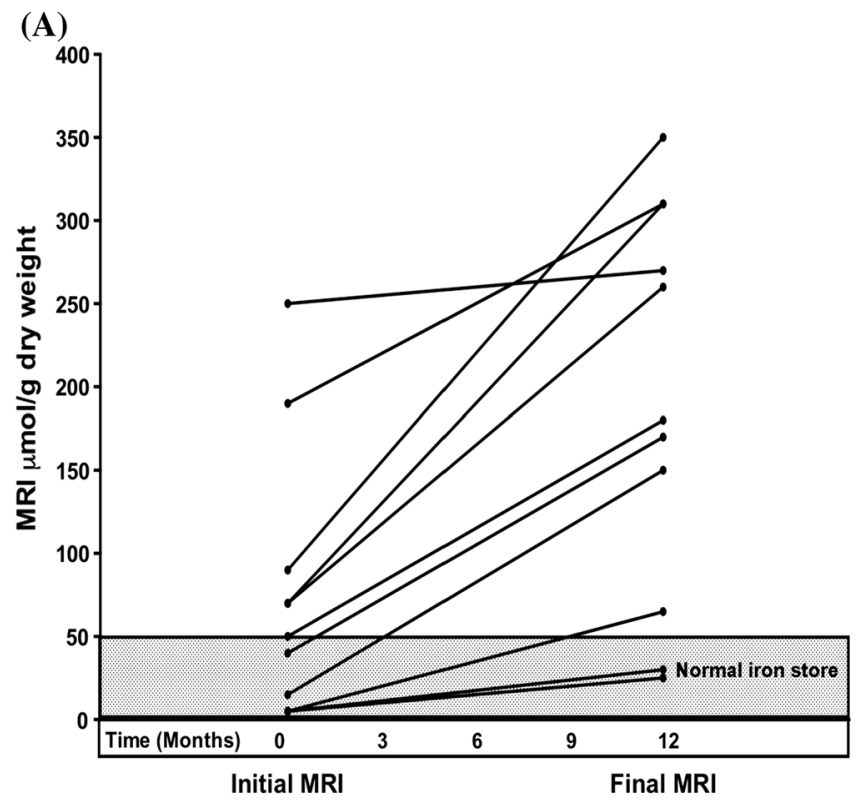

Fig. 3 Time course of hepatic iron stores studied by magnetic resonance imaging in hemodialysis patients (according to [8]). a Initial and final hepatic iron concentrations on magnetic resonance imaging (MRI) in 11 patients receiving iron therapy (median time is

biomarker targets [20]. Finally, data on the effect of iron infusion on LIC in dialysis patients studied by MRI are scarce: only one Australian study reported a mean LIC increase of $25.4 \mu \mathrm{mol} / \mathrm{g}$ dry weight on R2 relaxometry, 2 weeks after infusion of $10-20 \mathrm{mg} / \mathrm{kg}$ iron polymaltose (Maltofer ${ }^{\circledR}$ ) to 25 CKD patients, of whom five were on dialysis; the mean LIC increase at week 12 was $13 \mu \mathrm{mol}$ [20].

Further studies were called for by the recent KDIGO conference on the hypothetical risk of aggravation of liver diseases (e.g., viral hepatitis $\mathrm{B}$ and $\mathrm{C}$, non-alcoholic steatohepatitis) by iron accumulation in CKD patients, and even the theoretical risk of liver cancer in hepatitis $C$ viruspositive patients treated with IV iron [19]. Finally, it is important to find out whether or not dialysis patients with functional iron deficiency are more prone to iatrogenic iron overload than those with true iron deficiency.

\section{Morbidity and Mortality Related to Iron Overload in Hemodialysis Patients}

In the pre-ESA era, hemodialysis-associated hemosiderosis was a rare disorder classically comprising pigmented skin, cirrhosis, and heart failure associated with multiple endocrine disorders. It totally disappeared from dialysis centers in industrialized countries at least three decades ago but may again be seen in emerging countries (cf supra) $[3,75]$. Genetic hemochromatosis and secondary hemosiderosis

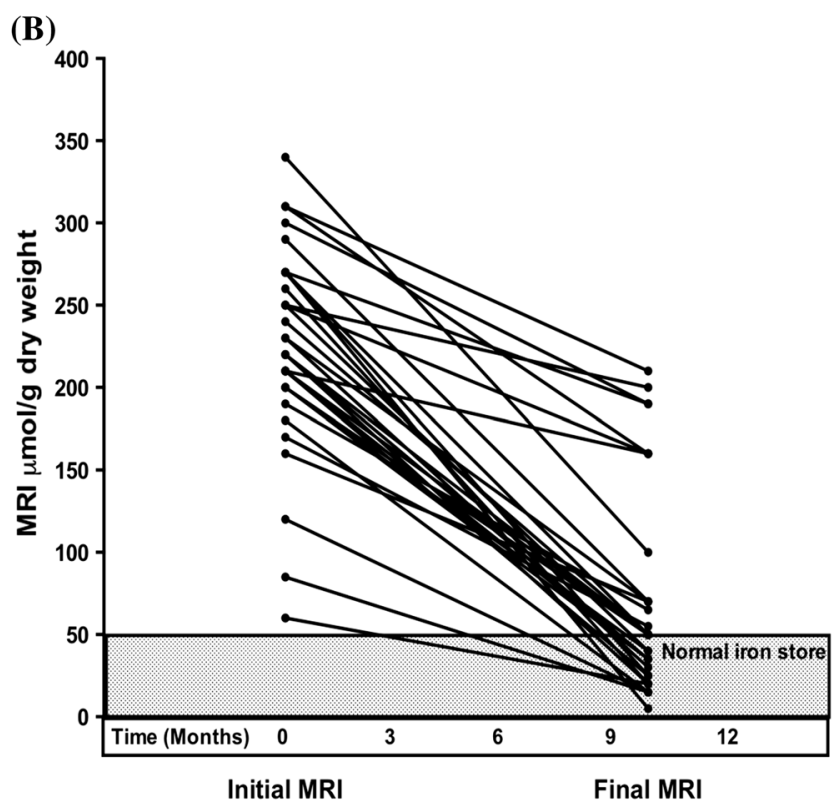

given in abcissa). b Initial and final hepatic iron concentrations on MRI in 33 patients with hepatic iron overload, after iron withdrawal $(n=19)$ or a major iron dose reduction $(n=14)$ (median time is given in abcissa)

related to hematological disorders are now diagnosed very early, far before development of any organ dysfunction $[10,53,56]$. Therefore, iron overload in dialysis patients in the ESA era might silently increase the burden of complications of dialysed CKD rather than induce a full clinical picture $[3,10,16]$. Thus, considering the scarcity of cirrhosis in historical studies and its slow onset, increased LIC in dialysis patients must rather be seen as a predictor of iron-mediated intensification of oxidative stress and inflammation, and disruption of homeostasis of iron-regulating hormones, that might lead to accelerated morbidity and mortality in this population.

Three methodologically rigorous observational studies showed no detrimental impact of high-dose IV iron on morbidity or mortality in dialysis patients (observation time after exposure of 1 month (with iterative rolling periods) in Feldman's study, two months in Miskulin's study, and 3 months in Kshirsagar's study) [77-79]; three other epidemiological studies with longer follow-up (1-2 years) show that excessive IV iron may increase mortality and cardiovascular events in hemodialysis patients; in our opinion, the longer follow-up of these latter studies may explain these discrepancies, and suggest that excess therapeutic iron may cause chronic cumulative toxicity if given for long periods [12-14].

In a prospective cohort study conducted in Taiwan, 1239 hemodialysis patients were followed for one year: 583 patients not receiving iron therapy were compared with 656 patients treated with IV ferric chloride hexahydrate [12]. 
The patients receiving IV iron were divided into three subgroups according the cumulative dose: $40-800 \mathrm{mg} /$ 6 months, $840-1600 \mathrm{mg} / 6$ months, and $1640-2400 \mathrm{mg} /$ 6 months [12]. The two subgroups with the higher cumulative iron doses had higher adjusted mortality [respective hazard ratios (HRs): 3.1 and 3.7] and more cardiovascular events (respective HRs: 3.5 and 5.1) than those not receiving IV iron and those who received less than $820 \mathrm{mg} /$ 6 months (or $136 \mathrm{mg} / \mathrm{month}$ ) [12].

Kuragano and coworkers prospectively monitored 1086 Japanese hemodialysis patients for 2 years and compared those on oral iron with those treated with IV iron, divided into three groups: oral iron plus very-low-dose IV iron, low-dose IV iron $(<200 \mathrm{mg} / \mathrm{month})$ and high-dose IV iron (>200 mg/month) [13]. They observed more cases of acute cardiocerebrovascular disease (HR: 6.02) and hospitalization (HR: 2.77) in the high-dose IV iron group, and increased risk of infections in both the low (HR: 1.78) and high (HR: 5.22) IV iron-treated groups [13]. High ferritin levels (consistently above $100 \mu \mathrm{g} / \mathrm{L}$, in accordance with Japanese guidelines [13]) were associated with the risk of acute cardiocerebrovascular disease (HR: 2.22), infections (HR: 1.76), and death (HR: 2.28) [13]. Moreover, a category switch from low to high ferritin (from less to more than $100 \mu \mathrm{g} / \mathrm{L}$ ) was also associated with an increased risk of acute cardiocerebrovascular disease (HR: 1.59) and death (HR: 6.18) [13].

The DOPPS study, using Cox regression models with multiple adjustments, analyzed associations between IV iron and clinical outcomes in 32435 hemodialysis patients followed for a median of 1.7 years (range 1-2.4) in 12 industrialized countries [14]. The authors found higher adjusted mortality in patients receiving 300-399 mg/month (HR: 1.13) and $400 \mathrm{mg} / \mathrm{month}$ or more (HR: 1.18) than in those receiving no iron or 1-99, 100-199, or $200-299 \mathrm{mg}$ of IV iron/month [14]. Similarly, the risk of hospitalization was higher (HR: 1.12) in patients receiving $300 \mathrm{mg} / \mathrm{month}$ or more of IV iron as compared with those receiving $100-199 \mathrm{mg} / \mathrm{month}$ [14]. Note that the toxic monthly iron doses found in the DOPPS study are very similar to those (400 mg/month) shown by Kalantar-Zadeh et al. to be associated with higher mortality among hemodialysis patients in the Da Vita cohort published 10 years ago [80].

The result of the Japanese study is in keeping with a recent US study showing that iron maintenance therapy at $200 \mathrm{mg} / \mathrm{month}$ is not associated with an increased shortterm risk of infections, contrasting that encountered with bolus monthly doses of $700 \mathrm{mg}$ [81].

These latter results are in line with the findings of a recent controlled trial of IV iron-sucrose versus oral iron in non-dialyzed CKD patients, showing increased serious cardiovascular and infectious events in IV iron-treated patients as compared with those receiving oral iron [82].
We postulate that three mechanisms might act synergistically to increase mortality and cardiovascular events in iron-overloaded hemodialysis patients, namely elevated hepcidin levels (synergized by fibroblast growth factor 23 [FGF 23]), increased oxidative stress, and arterial and cardiac structural changes.

Italian authors recently called for a critical re-evaluation of hepcidin levels in CKD patients, postulating that hepcidin is not intrinsically elevated in hemodialysis patients but rather reflects poor matching with healthy subjects and frequently excessive iron stores [83]. These authors postulated that hepcidin elevation may in fact be a physiologic defense mechanism against iron overload, and that it is preserved in patients with renal failure, even in those maintained on dialysis [83]. Indeed, high hepcidin-25 levels in dialysis patients with severe iron overload found on MRI have been shown to normalize in parallel with liver iron stores, supporting the latter hypothesis [8]. As high hepcidin-25 levels in hemodialysis patients were recently shown to be related to fatal and nonfatal cardiovascular events, the main physiopathological pathway linking these events to iron overload might involve the pleiotropic effects of hepcidin-25 [84], possibly in synergy with FGF 23 , which was recently shown to be induced by iron infusions and to exert cardiac toxicity [85, 86].

Oxidative stress, usually encountered in ESRD [87] and provoked by IV iron infusions [16] and iron overload (mediated by the release of labile, non-transferrin-bound iron) [88], might also adversely affect the vascular bed and act as a 'second hit'. In the dialysis population, excess iron might also play a direct role in cardiovascular complications by impairing endothelial function, as shown in patients with hereditary hemochromatosis [89], and also by directly favoring atherosclerosis [90, 91]. Conversely, taking into account data from post-mortem studies in the pre-ESA era, we suspect that myocardial iron deposits in heavily iron-overloaded dialysis patients might also play a paramount role in dialysis-related cardiovascular morbidity and mortality, especially sudden death [46-48 Thus, it is our opinion that well-powered cardiac T2*MRI studies are urgently needed in this subset of patients.

Beside these detrimental effects on the cardiovascular system and mortality, iron overload might affect several lineages of immune cells, leading to an increased risk of infection, as shown in some epidemiological studies: these effects could include CD4+ T-cell depletion associated with shortened cell lifespan, CD8+ CD28- T-lymphocyte expansion, impaired phagocytic activity, and microbial killing of polymorphonuclear leukocytes and monocytes [92]. In addition, because iron is an essential element for bacterial multiplication and virulence, iron overload owing to high doses of IV iron may increase the risk and severity of infections. Iron overload might also affect glucose 
regulation by inducing apoptosis of insulin-secreting pancreatic beta cells [93]. About $40 \%$ of dialysis patients worldwide are diabetic, and even a slight increase in iron stores has been suggested to play a role in the progression of macrovascular and microvascular complications of diabetes [94]. Diabetic dialysis patients might thus have a higher risk of complications from iron overload.

From a philosophical point of view, as the average life expectancy of dialysis patients in industrialized countries is about 4 years, some nephrologists have raised the fair question as to whether or not exposed patients will live long enough to develop organ failure from iron overload. We clearly are lacking the data necessary to answer this question. On the other hand, as postulated above, iron overload may act by disrupting homeostasis of hepcidin and FGF 23 (acting as a second hit) and increase the burden of cardiovascular diseases in diabetic patients (who now represent about $40 \%$ of dialysis patients) and patients with widespread atheroma disease (about $20 \%$ of old non diabetic patients). Finally, the question of long-term exposure to excessive iron may apply to this subset of young dialysis patients who have repeated graft failure, a relatively short time free of dialysis, and a long cumulative dialysis vintage (one or two decades or even more).

\section{Preventing Iron Overload in Dialysis Patients}

Iron overload in hemodialysis patients has been favored by reimbursement policies in the USA and many other industrialized countries, which have led to a dramatic increase in the use of IV iron in an attempt to avoid the high costs of ESA [9, 20]. The situation has been compounded by excessively high recommended doses of IV iron and, possibly, by erroneous iron biomarker targets which lead to supraphysiological iron stores [8,9]. In addition, nephrologists have come to fear the adverse effects of ESA while wrongly believing that iron IV products are nontoxic [20]. Major changes in the approach to iron therapy have occurred very recently. First, the KDIGO Controversies Conference on Iron Management in Chronic Kidney Disease, which took place in San Francisco in March 2014, recognized the entity of iron overload in hemodialysis patients (together with other adverse effects) and called for a research agenda on this topic [19]. Second, the Dialysis Advisory Group of the American Society of Nephrology proposed an aggiornamento on the policy of high 'blind' use of IV iron products in hemodialysis patients [20]. The Dialysis Advisory Group of the American Society of Nephrology has engaged in a profound and frank debate that has greatly contributed to understanding and overcoming this possible ongoing epidemic of iron overload in dialysis patients $[9,20]$. Recent reviews of anemia and iron therapy in $\mathrm{CKD}$, published in hematological and nephrology journals, have given a more balanced view, emphasizing not only the benefits but also the risks, including the danger of iron overload [95-98].

Quantitative MRI, which allows safe, non-invasive, repeated 'radiological liver biopsy' has recently been advocated by French [3, 30, 99] and Japanese authors [100] for routine iron-store monitoring of iron-treated dialysis patients (and also non renal patients on long-term treatment with IV iron products) [99]. Recent cohort studies of hemodialysis patients, combining quantitative MRI with data-mining and classical statistical methods, could yield both non-toxic doses of IV iron and accurate target values for biological markers of iron metabolism, thereby improving the safety of parenteral iron products in dialysis patients $[101,102]$. The aim of the first study, based on decision-tree learning and on MRI determination of hepatic iron content, was to identify a noxious pattern of parenteral iron administration in a prospective cohort of 199 hemodialysis patients treated for anemia with parenteral iron-sucrose and an ESA, in keeping with current clinical guidelines [101]. Hepatic iron stores were measured blindly by $\mathrm{T} 1$ and $\mathrm{T} 2 *$ contrast MRI, without gadolinium, coupled with $\mathrm{CHi}$-squared automatic interaction detection (CHAID) analysis [101]. The CHAID algorithm split the patients according to the monthly IV iron dose, with a single cutoff of $250 \mathrm{mg} / \mathrm{month}$. The odds ratio for hepatic iron overload on MRI was 3.9 (95\% CI: 1.81-8.4) with more than $250 \mathrm{mg}$ of IV iron/month versus less than $250 \mathrm{mg} / \mathrm{month}$ [101]. This MRI study suggests that the standard maximal monthly IV iron dose should be lowered to $250 \mathrm{mg}$ to lessen the risk of iron overload in dialysis patients [12-14]. The second study analyzed correlations between iron biomarkers and LICs measured blindly by quantitative MRI, and examined their accuracy for the diagnosis of iron overload in a prospective cohort of 212 hemodialysis patients treated with parenteral iron-sucrose and ESA for anemia, in keeping with current guidelines; the relationships were analyzed with Spearman's coefficient, logistic regression, and ROC curves [102]. Only serum ferritin showed a strong correlation with LIC (rho $=0.52,95 \%$ CI: $0.41-0.61, p<0.0001$, Spearman test). Likewise, in logistic analysis, only serum ferritin correctly classified the patients into those with normal liver iron stores (LIC $<50 \mu \mathrm{mol} / \mathrm{g}$ ) and those with elevated liver iron stores (LIC $>50 \mu \mathrm{mol} / \mathrm{g}$ ) (odds ratio 1.007; $95 \% \mathrm{CI}$ : 1.004-1.010) [101]. Serum ferritin was the most discriminatory iron biomarker in ROC curve analysis $(\mathrm{AUC}=0.767 ; 95 \%$ CI: 0.698-0.835). The optimal serum ferritin cut-offs were $160 \mu \mathrm{g} / \mathrm{L}$ for LIC $>50 \mu \mathrm{mol} / \mathrm{g}$ (mild overload) and $290 \mu \mathrm{g} / \mathrm{L}$ for $\mathrm{LIC}>200 \mu \mathrm{mol} / \mathrm{g}$ (severe overload) [102]. Having used quantitative MRI for more than 10 years in more than 250 dialysis patients at Claude Galien hospital in France, we have found a divergence between ferritin and LIC values in patients with 
inflammatory markers (e.g., high serum ferritin with normal or mildly increased LIC), a common situation partially related to the increasing prevalence of multiple comorbidities and medical complications in the population of hemodialysis patients; this is in line with ferritin modulation by inflammation and its role as an acute-phase reactant (unpublished data).

These results also suggest that ferritin targets in current guidelines (KDIGO, KDOQI, ERBP) should be lowered to avoid iron overload and its potential harmful effects [102].

The nephrology community is also rediscovering the smart, cautious Japanese strategy of iron therapy, which maintain optimal hemoglobin levels (somewhat lower than in Western countries) with minimal use of IV iron products and low ferritin levels $[21,103]$. It is tempting to speculate that the better overall survival of Japanese hemodialysis patients as compared with US and European patients, which is consistently found (despite multiple adjustments), might be, at least in part, related to lower use of IV iron products and, thus, less iron overload.

Major progress in the management of iron status in dialysis patients may soon come from investigational drugs that selectively inhibit hypoxia-inducible factor prolyl hydroxylases (HIF-PH) and stabilize hypoxia-inducible factor (HIF) [104]. HIF, a key regulatory protein, stimulates erythropoietin and transferrin production, reduces hepcidin production, and thereby modulates iron absorption and metabolism [104]. HIF-PH may also protect against ischemia-reperfusion damage) [104]. Phase III trials of HIF-PH in dialysis patients seek to manage iron stores very conservatively and cautiously, using oral iron and adopting a target ferritin value of at least $100 \mu \mathrm{g} / \mathrm{L}$.

Beside HIF stabilizers, iron administration via the dialysate (ferric pyrophosphate citrate/Triferic ${ }^{\circledR}$ ) and a ferric citrate-based phosphate binder (Auryxia ${ }^{\circledR}$ ) are new therapeutic options for compensating iron deficiency related to blood loss in hemodialysis patients and for providing the iron required for erythropoiesis [105-108]. Ferric pyrophosphate citrate/Triferic ${ }^{\circledR}$ rapidly delivers iron directly and safely to the bone marrow (5-7 mg iron) during hemodialysis sessions via the dialysate, efficiently matching the amount of iron required by ESA to generate red blood cells, without increasing ferritin levels [105]. The new phosphate binder composed of ferric citrate (Auryxia ${ }^{\circledR}$ ), beside its ability to chelate intestinal phosphate, strongly reduces the need for IV iron in dialysis patients, thus lowering the risk of iatrogenic iron overload and re-establishing oral iron as an efficient and well-tolerated source [106-108]. However, the Precautions section of the summary of product characteristics for Auryxia $^{\circledR}$ states that iron citrate may be absorbed probably via disrupted intestinal tight junctions in uremic patients, meaning that physiological regulation of iron absorption may be overstepped, resulting in iron overload [109-112].
Careful monitoring of iron stores in dialysis patients on Auryxia ${ }^{\circledR}$ is therefore recommended by the US Food and Drug Administration [109].

Finally, the nephrology community eagerly awaits the results of the academic prospective randomized trial PIVOTAL (launched by Kidney Research UK), which began in the UK in 2013, with lead investigator Prof. Ian Macdougall. This trial is comparing two iron therapy strategies based on iron sucrose: the first is in keeping with KDOQI 2006 and ERBP 2009 and is aimed at maintaining ferritin $>200 \mathrm{ng} / \mathrm{mL}$ and TSAT $>20 \%$, while the second is more liberal, with larger replenishment of iron stores (ferritin up to $700 \mathrm{ng} / \mathrm{mL}$ and TSAT up to $40 \%$ ). A total of 2080 incident patients with a dialysis vintage of less than 1 year will be followed for 4 years in 55 UK centers [113]. The primary endpoint will be the time to all-cause death or a composite of non fatal cardiovascular events (myocardial infarction, stroke and hospitalization for heart failure) [113]. This trial will not examine the possible benefit of more physiological targets of iron replenishment advocated by us and others $[8,9,15,16]$ and applied successfully in Japan for a decade [21]. This will require a specific trial.

\section{Conclusion}

Iron overload was previously considered rare in hemodialysis patients but is now an increasingly recognized clinical situation. It is therefore possible that many cases of iron overload in hemodialysis patients may in fact be owing to iatrogenic hemosiderosis. Recent studies based on quantitative MRI suggest a strong link between the IV iron dose and the risk of iron overload, and challenge both current iron biomarker cutoffs and clinical guidelines, especially with respect to recommended iron doses. In addition, some recent long-term observational studies suggest that excessive IV iron may increase mortality and cardiovascular events in hemodialysis patients. This recently rediscovered adverse effect of IV iron products has stimulated pathophysiological and epidemiological studies, and has led to profound ongoing changes in the concept of and clinical approach to IV iron therapy in dialysis patients, with the overriding aim of improving its safety.

\section{Compliance with Ethical Standards}

Conflict of interest Guy Rostoker: Grants received from NIPRO France, BAXTER-France, AMGEN-France, and GAMBRO-France. Member of the Amgen Aranesp European Board 2012-2014. Member of the Roche-France scientific board of the study Myriad 2012-2016. Payment for lectures for Fresenius Renal Pharma-France (2013 and 2015), Amgen-France (2013), and Novartis-France (2015). Nostarola Vaziri: No conflict of interest to declare.

Steven Fishbane: Research and consulting for Rockwell Medical and Keryx Inc. 
Funding This article had no funding.

Open Access This article is distributed under the terms of the Creative Commons Attribution-NonCommercial 4.0 International License (http://creativecommons.org/licenses/by-nc/4.0/), which permits any noncommercial use, distribution, and reproduction in any medium, provided you give appropriate credit to the original author(s) and the source, provide a link to the Creative Commons license, and indicate if changes were made.

\section{References}

1. Hörl WH. Clinical aspects of iron use in the anemia of kidney disease. J Am Soc Nephrol. 2007;18(2):382-93.

2. Eschbach JW, Egrie JC, Downing MR, et al. Correction of the anemia of end-stage renal disease with recombinant human erythropoietin: results of a combined phase I and II clinical trial. N Engl J Med. 1987;316(2):73-8.

3. Rostoker G, Griuncelli M, Loridon C, Cohen Y. Iatrogenic iron overload in dialysis patients. In: Suzuki H, editor. Updates in Hemodialysis. Rijeka: Intech; 2015. ISBN 978-953-51-2162-6.

4. KDOQI National Kidney Foundation. Clinical practice guidelines and clinical practice recommendations for anemia in chronic kidney disease in adults. Am J Kidney Dis 2006; 475 Suppl. 3:S16-85.

5. Kalantar-Zadeh K, Kalantar-Zadeh K, Lee GH. The fascinating but deceptive ferritin: to measure it or not to measure it in chronic kidney disease? Clin J Am Soc Nephrol. 2006;1(Suppl 1):S9-18.

6. Ali M, Rigolosi R, Fayemi AO, et al. Failure of serum ferritin levels to predict bone-marrow iron content after intravenous iron-dextran therapy. Lancet. 1982;1(8273):652-5.

7. Eschbach JW, Adamson JW. Iron overload in renal failure patients: change since the introduction of erythropoietin therapy. Kidney Int. 1999;55(Suppl 69):S35-43.

8. Rostoker G, Griuncelli M, Loridon C, et al. Hemodialysis-associated hemosiderosis in the era of erythropoiesis-stimulating agents: a MRI study. Am J Med. 2012;125(10):991-9.

9. Vaziri ND. Epidemic of iron overload in dialysis population caused by intravenous iron products: a plea for moderation. Am J Med. 2012;125(10):951-2.

10. Barton JC, Edwards CQ, Phatak PD, Britton RS, Bacon BR. Handbook of iron overload disorders. Cambridge: Cambridge University Press; 2010. ISBN-13: 9780521873437.

11. Canavese C, Bergamo D, Ciccone G, et al. Validation of serum ferritin values by magnetic susceptometry in predicting iron overload in dialysis patients. Kidney Int. 2004;65(3):1091-8.

12. Kuo KL, Hung SC, Lin YP, et al. Intravenous ferric chloride hexahydrate supplementation induced endothelial dysfunction and increased cardiovascular risk among hemodialysis patients. PloS One. 2012;7(12):e50295.

13. Kuragano T, Matsumura O, Matsuda A, et al. Association between hemoglobin variability, serum ferritin levels, and adverse events/mortality in maintenance hemodialysis patients. Kidney Int. 2014;86(4):845-54.

14. Bailie GR, Larkina M, Goodkin DA, et al. Data from the Dialysis Outcomes and Practice Patterns Study validate an association between high intravenous iron doses and mortality. Kidney Int. 2015;87(1):162-8.

15. Gaweda AE, Ginzburg YZ, Chait Y, et al. Iron dosing in kidney disease: inconsistency of evidence and clinical practice. Nephrol Dial Transplant. 2015;30(2):187-96.

16. Fishbane S, Mathew A, Vaziri ND. Iron toxicity: relevance for dialysis patients. Nephrol Dial Transplant. 2014;29(2):255-9.
17. Eknoyan G, Lameire N, Eckardt KU, et al. KDIGO Clinical practice guideline for anemia in chronic kidney disease. Kidney Int Suppl. 2012;2:279-335.

18. Locatelli F, Covic A, Eckardt KU, Wiecek A, Vanholder R; On behalf of the ERA-EDTA ERBP advisory board. Anaemia management in patients with chronic kidney disease: a position statement by the Anaemia Working Group of European Renal Best Practice (ERBP). Nephrol Dial Transplant 2009;24(2):348-54.

19. Macdougall IC, Bircher AJ, Eckardt KU, Obrador GT, Pollock CP, Stenvinkel P, Swinkels DW, Wanner C, Weiss G, Glenn M. Chertow for conference participants. Iron management in chronic kidney disease: conclusions from a "kidney disease: improving global outcomes" (KDIGO) controversies conference. Kidney Int. 2016;89:28-39. doi:10.1016/j.kint.2015.10. 002 .

20. Charytan DM, Pai AB, Chan CT, et al. Considerations and challenges in defining optimal iron utilization in hemodialysis. J Am Soc Nephrol. 2015;26(6):1238-47.

21. Yamamoto H, Tsubakihara Y. Limiting iron supplementation for anemia in dialysis patients: the basis for Japan's conservative guidelines. Semin Dial. 2011;24(3):269-71.

22. Himmelfarb J. Iron regulation. J Am Soc Nephrol. 2007;18(2):379-81.

23. Scientific advisory committee on nutrition. Iron and health. London: TSO; 2010.

24. Kautz L, Jung G, Valore EV, et al. Identification of erythroferrone as an erythroid regulator of iron metabolism. Nat Genet. 2014;46(7):678-84.

25. De Falco L, Sanchez M, Silvestri L, et al. Iron refractory iron deficiency anemia. Haematologica. 2013;98(6):845-53.

26. Sargent JA, Acchiardo SR. Iron requirements in hemodialysis. Blood Purif. 2004;22(1):112-23.

27. Otti T, Khajehdehi P, Fawzy A, et al. Comparison of blood loss with different high-flux and high-efficiency hemodialysis membranes. Am J Nephrol. 2001;21(1):16-9.

28. Kalocheretis P, Vlamis I, Belesi C, et al. Residual blood loss in single use dialyzers: effect of different membranes and flux. Int J Artif Organs. 2006;29(3):286-92.

29. Tsukamoto T, Yanagita M. Measurement of annual iron loss by blood sampling and residual blood after regular hemodialysis procedure in Japan. In: Annual Meeting of the American Society of Nephrology, Philadelphia (TH-PO858); 2014. https://www. asn-online.org/abstracts/.

30. Rottembourg J, Rostoker G. Use of intravenous iron supplementation in chronic kidney disease: interests, limits, and recommendations for a better practice. Neprol Therap. 2015. doi:10.1016/jnephro.2015.04.009.

31. Rosenblatt SG, Drake S, Fadem S, et al. Gastrointestinal blood loss in patients with chronic renal failure. Am J Kidney Dis. 1982;1(4):232-6.

32. Flint $\mathrm{S}$, Taylor $\mathrm{E}$, Beavis $\mathrm{J}$, et al. Increased iron requirement in hemodialysis patients on antiplatelet agents or warfarin. Nephron Clin Pract. 2009;113(1):c38-45.

33. Goicoechea M, Caramelo C, Ochando A, et al. Antiplatelet therapy alters iron requirements in hemodialysis patients. Am J Kidney Dis. 2000;36(1):80-7.

34. Auerbach M, Macdougall IC. Safety of intravenous iron formulations: facts and folklore. Blood Transfus. 2014;12(3): 296-300.

35. Macdougall IC, Geisser P. Use of intravenous iron supplementation in chronic kidney disease: an update. Iran J Kidney Disease. 2013;7(1):9-22.

36. Fishbane S, Frei GL, Maesaka J. Reduction in recombinant human erythropoietin doses by the use of chronic intravenous iron supplementation. Am J Kidney Dis. 1995;26(1):41-6. 
37. Albaramki J, Hodson EM, Craig JC, Webster AC. Parenteral versus oral iron therapy for adults and children with chronic kidney disease. Cochrane Database Syst Rev. 2012;1:CD007 857. doi:10.1002/14651858.CD007857.pub2.

38. European Medicines Agency. Available from URL: http://www. emea.europa.eu. Accessed 26 Mar 2016.

39. Anastassiades EG, Howarth D, Howarth J, et al. Monitoring of iron requirements in renal patients on erythropoietin. Nephrol Dial Transplant. 1993;8(9):846-53.

40. Van Wyck DB. Iron deficiency in patients with dialysis-associated anemia during erythropoietin replacement therapy: strategies for assessment and management. Semin Nephrol. 1989;9(1 Suppl 2):21-4.

41. Mittman N. Iron replacement in rHuEPO-treated dialysis patients: DOQI and beyond. Am J Kidney Dis. 1999;34(1):173-5.

42. Freburger JK, Ng LJ, Bradbury BD, et al. Changing patterns of anemia management in US hemodialysis patients. Am J Med. 2012;125(9):906-14.

43. Pisoni RL, Fuller DS, Bieber BA, et al. The DOPPS practice monitor for US dialysis care: trends through August 2011. Am J Kidney Dis. 2012;60(1):160-5.

44. Bailie GR, Larkina M, Goodkin DA, et al. Variation in intravenous iron use internationally and over time: the Dialysis Outcomes and Practice Patterns Study (DOPPS). Nephrol Dial Transplant. 2013;28(10):2570-9.

45. Karaboyas A, Zee J, Morgenstern H, et al. Understanding the recent increase in ferritin levels United States dialysis patients: potential impact of changes in intravenous iron and erythropoiesis-stimulating agent dosing. Clin J Am Soc Nephrol. 2015;10(10):1814-21.

46. Ali M, Fayemi AO, Rigolosi R, et al. Hemosiderosis in hemodialysis patients: an autopsy study of 50 cases. JAMA. 1980;244(4):343-5.

47. Pitts TO, Barbour GL. Hemosiderosis secondary to chronic parenteral iron therapy in maintenance hemodialysis patients. Nephron. 1978;22(4-6):316-21.

48. Gokal R, Millard PR, Weatherall DJ, et al. Iron metabolism in haemodialysis patients: aA study of the management of iron therapy and overload. Q J Med. 1979;48(191):369-91.

49. Simon P. Detoxification in hemosiderosis. Blood Purif. 1985;3(1-3):75-88.

50. Agroyannis B, Koutsicos D, Tzanatou-Exarchou H, et al. Combined recombinant human erythropoietin-blood letting strategy for treating anemia and iron overload in hemodialysis patients. Int J Artif Organs. 1991;14(7):403-6.

51. Cecchin E, De Marchi S, Querin F, et al. Efficacy of hepatic computed tomography to detect iron overload in chronic hemodialysis. Kidney Int. 1990;37(3):943-50.

52. Angelucci E, Brittenham GM, McLaren CE, et al. Hepatic iron concentration and total body iron stores in thalassemia major. N Engl J Med. 2000;343(5):327-31.

53. Brissot P, Troadec MB, Bardou-Jacquet E, et al. Current approach to hemochromatosis. Blood Rev. 2008;22(4):195-210.

54. Fischer R, Harmatz PR. Non-invasive assessment of tissue iron overload. Hematology Am Soc Hematol Educ Program. 2009;2009:215-21. doi:10.1182/asheducation-2009.1.215.

55. Alústiza JM, Castiella A, De Juan MD, et al. Iron overload in the liver: diagnostic and quantification. Eur J Radiol. 2007;61(3): 499-506.

56. Angelucci E, Barosi G, Camaschella C, et al. Italian Society of Hematology practice guidelines for the management of iron overload in thalassemia major and related disorders. Haematologica. 2008;93(5):741-52.

57. Gandon Y, Olivié D, Guyader D, et al. Non-invasive assessment of hepatic iron stores by MRI. Lancet. 2004;363(9406):357-62.
58. Rose C, Vandevenne P, Bourgeois E, et al. Liver iron content assessment by routine and simple magnetic resonance imaging procedure in highly transfused patients. Eur $\mathrm{J}$ Haematol. 2006;77(2):145-9.

59. Olthof AW, Sijens PE, Kreeftenberg HG, et al. Non-invasive liver iron concentration measurement by MRI: comparison of two validated protocols. Eur J Radiol. 2009;71(1):116-21.

60. Castiella A, Alústiza JM, Emparanza JI, et al. Liver iron concentration quantification by MRI: are recommended protocols accurate enough for clinical practice? Eur J Radiol. 2011;21(1):137-41.

61. St Pierre TG, Clark PR, Chua-Anusom W, et al. Noninvasive measurement and imaging of liver iron concentrations using proton magnetic resonance. Blood. 2005;105(2):855-61.

62. Carniero AA, Fernandes JP, De Araujo DB, et al. Liver iron concentration evaluated by two magnetic methods: magnetic resonance imaging and magnetic susceptometry. Magn Res Med. 2005;54(1):122-8.

63. Wood JC, Enriquez C, Ghugre N, et al. MRI R2 and R2* mapping accurately estimates hepatic iron concentration in transfusion-dependent thalassemia and sickle cell disease patients. Blood. 2005;106(4):1460-5.

64. Anderson LJ, Holden S, Davis B, et al. Cardiovascular T2-star (T2*) magnetic resonance for the early diagnosis of myocardial iron overload. Eur Heart J. 2001;22(23):2171-9.

65. Hankins JS, McCarville MB, Loeffler RB, et al. R2* magnetic resonance imaging of the liver in patients with iron overload. Blood. 2009;113(20):4853-5.

66. Rostoker G, Cohen Y. Magnetic resonance imaging repercussions of intravenous iron products used for iron-deficiency anemia and dialysis-associated anemia. J Comput Assist Tomogr. 2014;38(6):843-4.

67. Rienso-European Medicines Agency. http://www.ema.europa.eu/ docs/en_GB/document_library/EPAR_-_Product_Information/ human/002215/WC500129749.pdf. Accessed 18 Dec 2015.

68. Ferrari P, Kulkarni H, Dheda S, et al. Serum iron markers are inadequate for guiding iron repletion in chronic kidney disease. Clin J Am Soc Nephrol. 2011;6(1):77-83.

69. Ghoti H, Rachmilewitz EA, Simon-Lopez R, et al. Evidence for tissue iron overload in long-term hemodialysis patients and the impact of withdrawing parenteral iron. Eur $\mathrm{J}$ Haematol. 2012;89(1):87-93.

70. Fishbane S, Miyawaki N, Masani N. Hepatic iron in hemodialysis patients. Kidney Int. 2004;66(4):1714-5.

71. Beshara S, Lundqvist H, Sundin J, et al. Kinetic analysis of 52 Fe-labelled iron (III) hydroxide-sucrose complex following bolus administration using positron emission tomography. Br J Haematol. 1999;104(2):288-95.

72. Beshara S, Lundqvist H, Sundin J, et al. Pharmacokinetics and red cell utilization of iron (III) hydroxyde-sucrose complex in anaemic patients: a study using positron emission tomography. Br J Haematol. 1999;104(2):296-302.

73. Beshara S, Sörensen J, Lubberink M, et al. Pharmacokinetics and red cell utilization of ${ }_{52} \mathrm{Fe} /{ }_{59} \mathrm{Fe}$-labelled iron polymaltose in anaemic patients using positron emission tomography. Br J Haematol. 2003;120(5):853-9.

74. Maker GL, Siva B, Batty KT, et al. Pharmacokinetics and safety of Deferasirox in subjects with chronic kidney disease undergoing haemodialysis. Nephrology (Carlton). 2013;18(3):188-93.

75. Alnahal AA, Tahan M, Fathy A, Fathy T. Effect of deferoxamine therapy on insulin resistance in end-stage renal disease patients with iron overload. Saudi J Kidney Dis Tranplant. 2014;25(4):808-13.

76. Agence Nationale de Sécurité du Médicament et des produits de Santé (ANSM). Traitement de l'anémie des hémodialysés par solutions de fer IV: l'ANSM rappelle la nécessité de respecter 
les schéma posologiques de l'AMM-Point d'information du 18/02/2013.ansm.sante.fr.

77. Feldman HI, Joffe M, Robinson B, et al. Administration of parenteral iron and mortality among hemodialysis patients. J Am Soc Nephrol. 2004;15(6):1623-32.

78. Miskulin DC, Tangri N, Bandeen-Roche K, et al. Intravenous iron exposure and mortality in patients on hemodialysis. CJASN. 2014;9(11):1930-9.

79. Kshirsagar AV, Freburger JK, Ellis AR, Winkelmayer WC, Brookhart A. Intravenous iron supplementation practices and short-term risk of cardiovascular events in hemodialysis patients. Plos One. 2013;8(11):e78930. doi:10.1371/journal. pone.0078930 (eCollection 2013).

80. Kalantar-Zadeh K, Regidor DL, McAllister CJ, et al. Time-dependent associations between iron and mortality in hemodialysis patients. JASN. 2005;16(10):3070-80.

81. Brookhart MA, Freburger JK, Ellis AR, et al. Infection risk with bolus versus maintenance iron supplementation in hemodialysis patients. JASN. 2013;24(7):1151-8.

82. Agarwal R, Kusek J, Pappas M. A randomized trial of intravenous and oral iron in chronic kidney disease. Kidney Int 2015. doi:10.1038/ki.2015.163.

83. Valenti L, Messa P, Pelusi S, et al. Hepcidin levels in chronic hemodialysis patients: a critical evaluation. Clin Chem Lab Med. 2014;52(5):613-9.

84. Van der Weerd NC, Grooteman MP, Bots ML, et al. Hepcidin25 is related to cardiovascular events in chronic haemodialysis patients. Nephrol Dial Transplant. 2013;28(12):3062-71.

85. Hyrszko T, Rydzewska-Rosolowska A, Brzosko S, et al. Low molecular weight iron dextran increases fibroblast growth factor-23 concentration, together with parathyroid hormone decrease in hemodialyzed patients. Ther Apher Dial. 2012;16(2):146-51.

86. Grabner A, Amaral AP, Schramm K, et al. Activation of cardiac fibroblast growth factor receptor 4 causes left ventricular hypertrophy. Cell Metab 2015. doi:10.1016/j.cmet.2015.090.002

87. Himmelfarb J, Stenvinkel P, Ikizler TA, Hakim RH. The elephant in uremia: oxidant stress as an unifying concept of cardiovascular disease in uremia. Kidney Int. 2002;62:1524-38.

88. Slotki I, Cabantchik ZI. The labile side of iron supplementation in CKD. J Am Soc Nephrol. 2015;26(11):2612-9.

89. Gaenzer H, Marschang P, Sturm W, et al. Association between increased iron stores and impaired endothelial function in patients with hereditary hemochromatosis. J Am Coll Cardiol. 2002;40(12):2189-94.

90. Drüeke T, Witko-Sarsat V, Massy Z, et al. Iron therapy, advanced oxidation protein products and carotid artery intimamedia thickness in end-stage renal disease. Circulation. 2002;106(17):2212-7.

91. Reis KA, Guz G, Ozdemir H, et al. Intravenous iron therapy as a possible risk factor for atherosclerosis in end-stage renal disease. Int Heart J. 2005;46(2):255-64.

92. Pahl MV, Vaziri ND. Immune function in chronic kidney disease. In: Kimmel P, Rosenberg M, editors. Chronic renal disease, chap 24. San Diego: Academic Press-Elsevier; 2015. p. 285-97. doi:10.1016/B978-0-12-411602-3.00024-X.

93. Masuda Y, Ichii H, Vaziri ND. At pharmacologically relevant concentrations intravenous iron preparations cause pancreatic beta cell death. Am J Transl Res. 2013;6(1):64-70.

94. Fernández-Real JM, Manco M. Effects of iron overload on chronic metabolic diseases. Lancet Diabetes Endocrinol. 2014;2(6):513-26.

95. Vaziri ND. Understanding iron: promoting its safe use in patients with chronic kidney failure treated by hemodialysis. Am J Kidney Dis. 2013;61(6):992-1000.
96. Ribeiro S, Belo L, Reis F, Santos-Silva A. Iron therapy in chronic kidney disease: recent changes, benefits and risks. Blood Rev. 2015. doi:10.1016/j.blre.2015.07.006.

97. Drüeke TB, Massy ZA. Oral or intravenous iron for anemia correction in chronic kidney disease? Kidney Int. 2015;88(4):673-5. doi:10.1038/ki.2015.189.

98. Tanaka S, Tanaka T. How to supplement iron in patients with renal anemia. Nephron Pract. 2015;131(2):138-44.

99. Polin V, Coriat R, Perkins G, et al. Iron deficiency: from diagnosis to treatment. Dig Liver Dis. 2013;45(10):803-9. doi:10. 1016/j.dld.2013.02.019 (Epub 2013 Apr 11).

100. Shibata M, Taniguchi S. Iron supplementation therapy in endstage renal disease patients on maintenance hemodialysis. Cardiovasc Haematolog Disord Drug Targets. 2013;13:237-42.

101. Rostoker G, Griuncelli M, Loridon C, et al. Maximal standard dose of parenteral iron for hemodialysis patients: an MRI-based decision tree learning analysis. Plos One. 2014;9(12):e115096. doi:10.1371/journal.pone.0115096 (e Collection 2014 ).

102. Rostoker G, Griuncelli M, Loridon C, et al. Reassessment of iron biomarkers for prediction of dialysis iron overload: an MRI study. Plos One 2015;10(7):e0132006. doi:10.1371/journal. pone.0132006 (eCollection 2015)

103. Ogawa C, Tsuchiya K, Kanda F, Maeda T. Low levels of serum ferritin lead to adequate hemoglobin levels and good survival in hemodialysis patients. Am J Nephrol. 2014;40(6):561-70.

104. Del Vecchio L, Locatelli F. Anemia in chronic kidney disease patients: treatment recommendations and emerging therapies. Expert Rev Hematol. 2014;7(4):495-506.

105. Gupta A, Lin V, Guss C, Pratt R, Ikizler TA, Besarab A. Ferric pyrophosphate citrate administered via dialysate reduces erythropoiesis-stimulating agent use and maintains hemoglobin in hemodialysis patients. Kidney Int. 2015. doi:10.1038/ki.2015. 203.

106. Umanath K, Jalal DI, Greco BA, for the Collaborative Study Group, et al. Ferric citrate reduces intravenous iron and erythropoiesis-stimulating agent use in ESRD. J Am Soc Nephrol. 2015;26(10):2578-87.

107. Qunibi WY. Is it too much of a good thing? A new era in phosphate binder therapy in ESRD. J Am Soc Nephrol. 2015;26(10):2311-3.

108. Nakanishi T, Hasuike Y, Nanami M, Yahiro M, Kuragano T. Novel iron-containing phosphate binders and anemia treatment in CKD: oral iron intake revisited. Nephrol Dial Transplant. 2015. doi:10.1093/ndt/gfv268.

109. FDA. Auryxia ${ }^{\circledR}:$ summary of the characteristics of the product. http://www.accessdata.fda.gov/drugsatfda_docs/label/2014/205 874s001lbl.pdf. Accessed 18 Dec 2015.

110. Vaziri ND, Zhao YY, Pahl MV. Altered intestinal microbial flora and impaired epithelial barrier structure and function in CKD: the nature, mechanisms, consequences and potential treatment. Nephrol Dial Transplant. 2015. doi:10.1093/ndt/ gfv095.

111. Vaziri ND, Yuan J, Rahimi A, et al. Disintegration of colonic epithelial tight junction in uremia: a likely cause of CKD-associated inflammation. Nephrol Dial Transplant. 2012;27(7):2686-93.

112. Vaziri ND, Yuan J, Nazertehrani S, et al. Chronic kidney disease causes disruption of gastric and small intestinal epithelial tight junction. Am J Nephrol. 2013;38(2):99-103.

113. EU Clinical Trials Register: Proactive IV Iron Therapy for Haemodialysis Patients (PIVOTAL), 2013. Available from URL: https://www.clinicaltrialsregister.eu/ctr-search/trial/2013002267-25/GB. Accessed 27 June 2014. 